\title{
Attitude toward Advertising in General and Attitude toward a Specific Type of Advertising - A First Empirical Approach
}

\section{- Dianoux Christian, Linhart Zdeněk, Vnoučková Lucie}

\begin{abstract}
The paper examines based on international research the differences between results of studies focused on consumers' attitude toward advertising. The aim of this paper is to show that it is possible to find situations where the influence of attitudes towards specific ads in general (ASG) on attitudes toward advertising ( $\mathrm{Aad}$ ) can be observed and also it is possible to find no influence of attitudes toward ads in general (AG) on Aad. The paper shows that the problem comes from the definition of AG. The experiments described in this paper detect attitudinal differences toward advertising in general among studied nations depending on the type of advertising. The research encompasses respondents from three countries with different economic and cultural backgrounds (Germany, Ukraine and USA). The data were collected based on a quantitative survey and experiment among university students. The results show that the concept of AG is in some cases too broad. Differences between AG were confirmed between Ukraine and other countries. The respondents from Germany are according to AG more pessimistic and the respondents from the USA are more optimistic. This disparity was explained by a significant difference in Orthodox and Atheist religion compared to the other religions.
\end{abstract}

Key Words: attitude toward advertising, attitude toward advertising in general, hard and soft sell, religion, Germany, Ukraine, USA

JEL Classification: M37

\section{INTRODUCTION}

Consumers' attitudes toward an ad (Aad) have offered a critical theoretical construct since 1981, with the publication of two influential articles (Mitchell \& Olson, 1981; Shimp, 1981). Following these seminal articles, various studies were dedicated to demonstrating the effects of $\mathrm{Aad}^{1}$ on brand attitudes and purchase intentions (e.g., Gardner, 1985; MacKenzie, Lutz, \& Belch 1986; McKenzie, \& Lutz, 1989). Other studies show that Aad notably depends on attitudes toward advertising in general (Lutz, McKenzie, \& Belch, 1983; Muehling, 1987; MacKenzie \& Lutz, 1989; Mehta, 2000). Yet attitudes toward advertising in general (AG) ${ }^{2}$ and their influence on

1. Attitudes toward an ad (Aad) can be define as thoughts and emotions of consumer related to the ad (Kirmani a Campbell, 2009). Other authors define Aad as emotional reaction of consumer (i.e. interesting/boring, symphatic/annoying etc.) (Lutz et al., 1983; MacKenzie, 1986). It is also possible to mention that there are another two aspects of ad perception - cognitive and emotional (Shimp 1981). These attitudes can obtain also emotional reactions (i.e. luck, happiness etc.) and evaluation reaction (i.e. trustfulness or information bareness) (Baker a Lutz, 2000).

2. Lutz (1985) defines attitude towards the ad in general (AG) as thought predisposition of reaction (positive or negative) based on the shown advertisements. 
advertising effectiveness have rarely been studied in cross-national studies (Mehta, 2000). This gap is puzzling, in that AG seems likely to differ across countries (Durvasula, Lysonski, \& Mehta, 1999) who are proposing ro differentiate the countries studied, as "consumers in India and Singapore analyze advertisements differently. It would, therefore, appear to be inappropriate to standardize all advertising campaigns." (p. 57).

Alongside these results, it is surprising that a number of advertisements are used uniformly over several countries and seem reach satisfactory efficiency scores in each country. It is therefore possible that other factors influence that.

One of these factors is maybe the kind of advertising that people like. Indeed it is not because somebody likes something in general that he likes a precise thing. In this way Soo and Chia (2007) have demonstrated that there can be differences between attitudes toward TV ads and magazine ads. Following this reasoning we supposed to here that the attitude toward the advertising in general can vary depending on the type of ad.

The objective of this paper is to show that the problem comes from the definition of AG. We try to show from an experiment if it is possible to detect by country any attitudinal differences toward advertising in general. Differences can have different strengthens and variable influence on Aad depending on the type of advertising. The final concept which is the most managerially interesting is to predict Aad as the attitude toward specific type of ad. Indeed, the concept of AG is in some cases too broad and needs to be replaced by more accurate measurements which focus on specific features of ads. We will try to show that the concept of AG must be accompanied by more precise measurements which take into account the main features of advertising.

We start with a theoretical background to clarify the key constructs of attitude toward advertising in general and attitude toward an ad, as well as their relationship. The journal articles mentioned in the theoretical background may look out-of-date, but we work with the original concept of Aad, AG and $\mathrm{ASG}^{3}$. Additionally, there are only rare studies focusing on the theme. Therefore we cite authors and studies from the beginning of the concept till current surveys. The paper is therefore focused on the specific area, where only mentioned surveys and researches can be deeply analyzed. Moreover the paper presents new factors which may influence resultant relationships observed by different authors all over the world. Thus, in light of our theoretical background and empirical evidence, we present the international context of our research and develop research questions. Furthermore, we outline our methodology and research findings, followed by a discussion, conclusion, and limitations.

\section{THEORETICAL BACKGROUND}

A lot of studies show that Attitude toward the advertising (Aad) depends on attitudes toward advertising in general (Lutz, McKenzie, \& Belch, 1983; Muehling, 1987; MacKenzie \& Lutz,

3. ASG states for attitude toward specific ad. In the paper, specific ads are divided into hard sell and soft sell. Soft sell ads display only picture of the product and try to evoke positive emotions and feelings. Hard sell ads contain more information about the product; those ads focus mainly on the cognition of the respondent. 
1989; Mehta, 2000). In their structural model of the cognitive and affective antecedents of Aad, MacKenzie and Lutz (1989) suggest attitude toward advertising in general exerts an important influence, along with several variables (i.e., ad credibility, ad perceptions, attitude toward advertiser, and mood). The authors assess four ad exposure situations (i.e., pure affect transfer, message-based persuasion, contextual evaluation transfer, and dual mode persuasion) that reflect varying levels of both ad message and ad execution involvement; in all cases, AG served as an important construct for explaining ad-based persuasion mechanisms.

Despite widespread acceptance of this theory, specific research on the relationship between AG and Aad is rare. Mehta (2000) cites a few studies dedicated to research the effects of AG on advertising recall (Donthu, Cherian, \& Bhargava, 1993) or on consumer involvement in specific advertisements (James \& Kover, 1992). His research also reveals the influence of AG on the overall attention paid to print advertisements (measured as brand recall) and on persuasiveness (measured as buying interest).

Some other research show that AG differs significantly across countries (Durvasula, Lysonski, \& Mehta, 1999).

However, in admitting the above hypotheses (AG influences Aad and AG differs across countries), it seems not very easy to understand why we observe more and more identical advertising campaigns which work very well in different countries.

This apparent paradox could be easily explained if AG differs between countries but do not influence automatically Aad because people answer to general question on AG with a standard in mind and this standard can be identical or not with the ad they see. For example, if for the consumer the standard is an informative ad and he has a positive or negative attitude toward informative ad, there will be a link between AG and Aad essentially when the ad is informative. If the ad is only an image with a beautiful girl and a claim, there will be maybe not any link between AG and Aad. In this case, we can have the following process if the advertiser has to choose between two campaigns (see Table 1).

Tab. 1 - Example of two different relationships between AG and Aad. Source: authors

Campaign A (with an informative ad)

case where AG is a good gauge because the consumer does think at the A-type of ad -here an informative ad- when he answers to the questions about AG)

\begin{tabular}{|l|l|l|}
\hline Country 1 & $\begin{array}{l}\text { ASGinfo+++ (Attitude } \\
\text { toward Specific informative } \\
\text { ads in General)=> Aada }+++\end{array}$ & $\mathrm{AG}+++=>$ Aada +++ \\
\hline Country 2 & $\begin{array}{l}\text { ASGinfo- - (Attitude toward } \\
\text { Specific informative ads in } \\
\text { General)=> Aada- - }\end{array}$ & AG- - => Aada- - \\
\hline
\end{tabular}


Campaign B (with a sensual ad)

(case where AG is not a good gauge because the consumer does think at the A-type and not at B-type of ad -here a sensual ad- when he answers to the questions about AG)

\begin{tabular}{|l|l|l|}
\hline Country 1 & $\begin{array}{l}\text { ASGsensual+ (Attitude } \\
\text { toward Specific sensual ads } \\
\text { in General) }=>\text { Aadb }+\end{array}$ & AG +++ no link with Aadb + \\
\hline Country 2 & $\begin{array}{l}\text { ASGsensual+++ (Attitude } \\
\text { toward Specific sensual ads } \\
\text { in General) }=>\text { Aadb }+++\end{array}$ & AG- - no link with Aadb +++ \\
\hline
\end{tabular}

Furthermore, we can imagine that campaign B is a communication which use soft-sell arguments and ASG is the liking of soft-sell advertising type in both countries which justified the same campaign, because this kind of advertising is liked (more or less) whatever the country compare to hard-sell communication (campaign A). This hypothesis is consistent with the observation of Okazaki et al (2010); they show that international identical advertising campaigns are more oriented around soft-sell communication than hard-sell communication. In other words, that means AG is not always a strong predictor of AG toward a specific type of advertising; thus we need to measure Attitude toward specific advertising in general (ASG).

Indeed, as a few cross-national researches have been made focusing on this topic (Mehta, 2000), it is possible that the relationship between AG and Aad has been observed in certain circumstances and could be not observed in all cases. So we can state the following hypothesis: If the advertising is conform to the ad standard expected by consumer when he answers to the questions on AG, we can observe a relationship between AG and Aad. The ad standard could be described as an advertising type that the consumer has in mind when he answers to questions about his thoughts on advertising. Thus it is possible to describe strong relationship between AG and Aad in some circumstances and not in others because of the general advertising reference the consumer has in his mind when he answers to the questions.

This could mean that, in addition to the attitude the consumer may have toward advertising in general, specific attitude variations can play an important role.

Thus we could have the same relation that Soo and Chia (2007) have shown for attitude toward commercial ads in general (Atv) which can be different than attitude toward print advertising in general (Aprint). According to de Mooij (1999), media structures can summarize acquired cultural values, such as individualistic cultures rely more on newspapers but collectivist cultures prefer TV in their overall media consumption. Bush, Smith, and Martin (1999) have revealed the opposite: the amount of TV viewing is positively associated with AG. The advertising data for the two countries in our study support claim of Bush, Smith, and Martin (1999) and don't support de Mooij's (1999) finding. According to the results of Dianoux, Linhart \& Ogjanov (2012) the attitudes toward advertising in general (measured by: advertising in general is bad/good, unfavorable/favorable, negative/positive with a seven-point semantic differential pairs) differ significantly across the two European countries with French people who tend to like advertising in general $(M=4.30)$, and Czech people who tend to dislike advertising in general $(M=3.81)$ out of 7-point scale ( $1=$ totally dislike, $7=$ totally like). Questions of Pollay and Mittal (1993) 
are showing internationally different answers, which are explaining AG, Aad and Ab transfers between the Czech Republic and France.

Summary, there are general attitudes which influence Aad but those could have significant distortions depending on the type of advertising used. It can be supposed this is not the fact of liking the advertising in general but more importantly the fact of liking a particular type of ad. It is obvious that if a consumer does absolutely not like the advertising in general, all the ads appear annoying (except maybe some specific ads). But out of these extreme and rare cases, what really matters is the type of ad that people like. The fact of liking advertising in general is a whole interesting concept but managerially irrelevant, especially in an international context where consumers can have different advertising standard in mind which vary from one country to another (and also vary for the same consumer depending on the ads he has in mind). So the aim of this paper is to show that:

It is possible to find situations where it is possible to observe influence of ASG on Aad and no influence of AG on Aad.

\section{METHODS}

The chapter presents methods used; we present firstly the research concept, research sample, measurement used and the experiment will be described.

\subsection{Research concept}

Research encompasses three countries with different economic and cultural backgrounds. Groups of respondents were from Germany, Ukraine and USA. This choice is justified considering the differences in AG between nations. It is worth to validate this first result to simplify questionnaires in further researches.

\subsection{Sample}

The sample of respondents contains university students in Ukraine, USA and Germany. Student sample was used because most cross-national studies use student samples, which offer appealing homogeneity (e.g., Durvasula et al., 1993). Students were also chosen for the survey because those youth persons present and form the perception of advertising today and in the future. The research (this paper presents first approach to the study) made contained together 276 (undergraduate and graduate) business students attending universities in researched countries from Germany ( $=78)$, Ukraine ( $\mathrm{N}=108)$ and USA ( $=90)$. According to the studies presented in marketing research by other authors, the sample size we present in this paper is sufficient, because of the mentioned homogeneity of the sample. Most of the authors present their studies using approx. 50 students per country/selected study and the results are valid and reliable. Validity and reliability was also tested on student samples. The student sample is also interesting for research because of students have generally more favorable attitudes toward marketing and advertising (Roberts \& Manolis, 2000).

The sample was selected solely for the purposes of the survey. Answers of respondents were categorised according to identification questions that formed the first part of the questionnaire. 
In the survey, the measurement was based on closed questions with one or several possible answer(s) that had been selected based on the study of literature, documents and other related surveys.

\subsection{Measures}

During the course of a business class, respondents from each country answered questions about their attitudes toward advertising in general. To measure it, the three items were used. Subjects were asked to indicate the extent to which they agreed or disagreed with three statements on a seven-point scale: Overall, I consider advertising a good thing; My general opinion about advertising is unfavorable (reverse coded); Overall, I do like advertising. The original Muehling's scale (1987) used three items "very general semantic-differential item pairs" (p.33): My attitude toward advertising is Good/Bad, Favorable/Unfavorable, Positive/Negative). Recently, two of these three items were used by Rojas-Méndez, Davies, and Madran (2009): Overall, I consider advertising a good thing, and Overall, I strongly dislike, somewhat dislike, feel neutral, somewhat like, and strongly like advertising.

To measure attitude toward specific advertising in general, we have taken in account:

- The attitude toward advertising in specific media (Tan, Chia, 2007) and adapted Pollay and Mittal's scale to the billboard media which is studied in this paper (e.g. Overall, I consider billboard ads a good thing).

- The attitude toward soft-sell and hard-sell advertising (Okazaki et al., 2010) and we have retained the following items: In general, how likely do you like or not billboard ads which are (7-point scale: I like very much $=7$; I totally dislike $=1$ ).

The attitudes measured are stated in Table 2 below:

Tab. 2 - Hard sell vs. soft sell. Source: authors.

\begin{tabular}{|l|l|}
\hline For Hard-sell appeal: & For Soft-sell appeal: \\
\hline - concrete (Thinking dimension) & - entertaining (Image Dimension) \\
- feature centered (Fact dimension) & - visually oriented (Image Dimension) \\
- informative (Fact dimension) & - emotional (Feeling Dimension) \\
- instructive (Explicitness dimension) & - abstract (Feeling Dimension) \\
\hline
\end{tabular}

We associate hard-sell with impact of facts and soft-sell ads with importance of social approval. Semantic differential was applied to identify nuances in respondents' attitudes through the questionnaire. Respondents' reactions to target statements and their attitudes to the given matter were restricted by offering a set of several statements. The extremes of the seven-point scale represented bipolar concepts of the evaluation dimension. Using a scale of 1 to 7 , respondents expressed their inclination towards one of the preset extreme statements or, provided it was not possible to favor either of the sides, selected a median, neutral value (the median value was characterized by number 4). The scale permitted not only the specification of respondents' attitudes, 
but also their intensity. Semantic differential and its use in marketing studies was tested and approved. Therefore we used the same measures for our study. To measure attitude toward the ad, we have adapted both standardized scales by Okazaki et al. (JA2010 and JIM2010) and the questions and scales measuring believability and irritation by Bhat, Leigh, and Wardlow (1998): "For you, this ad is rather: (7-point Likert scale with surely disagree=1 and surely agree=7): boring (reversed), irritating (reversed), disturbing (reversed), credible, good, interesting." Moreover we have added the item by MacKenzie, Lutz, \& Belch (1986): "To what extent do you like or dislike this ad: (7-point Osgood scale with like = 7; not like = 1)" for the experimental ads (experimental ads were drawn by authors of the study to measure hard and soft sells) and for four real ads (copied from real newspapers as re-test).

Another part of questionnaire was based on Muehling's scale (1987) which measure attitude towards institution and instrument (Durvasula et al., 1993), economical versus social aspects (Durvasula et al., 1999), verbal measurement of affective reaction of respondents (Derbaix, 1995), attitude of respondents toward an ad (Aad) (Coulter, 1998; MacKenzie, Lutz \& Belch, 1986), engagement of consumer (Consumer Involvement Profile, CIP) by Kapferer \& Laurent (1985).

The analysis was carried out using the Microsoft Excel 2007, and SPSS programmes. The conclusiveness of the outputs and relationships obtained were supported by the tools of descriptive statistics, for testing of results the analysis of correlation and ANOVA were used to review the outcomes. Again, we used mentioned statistical methods based on the reliability of the study. We followed standardized concept of reviewing the results in the specific area. Next paper may use more sophisticated methods, such as SEM or PLC to compare the results.

\subsection{Experiment}

The questionnaire had three parts. First part (A) was focused on AG, second part (B) was measuring Aad (hard sell and soft sell) and the third part (C) was focusing on brand intention (Bi) and changing attitude towards brand (Ab).

In the first step, we have administrated the first part of the questionnaire to measure AG and ASG. In a second step, we have separated respondents from each country in two groups: one exposed to an ad for a new brand of mobile phone which used soft-sell argumentation and one exposed to an ad for the same new brand of mobile phone which used hard-sell argumentation. The billboard ad (soft-sell for one group and hard-sell for another group in each country) was projected on the wall during all the duration of the second part of the questionnaire. The two ads were the same in each country, except for the language used; we translated and back-translated all content. After exposition, we asked respondents to complete a follow-up questionnaire.

Finally during the third step, we projected on the wall four ads (10 seconds each) to all the participants (two with soft-sell arguments for L'Oréal and Bic and two with hard-sell arguments for Audi and Nikon). The billboard ads were in English because we wanted to keep the same ads in all countries. After the exposition, we asked respondents to complete the final part of the questionnaire (measures of Aad for the four ads).

Respondents from Ukraine, and Germany filled paper questionnaire. Respondents from USA have not filled their answers on paper form questionnaire for scanner but online at http://vertiroute.eu/forms. 
All items originally in English were translated into languages of the specific country using the procedure suggested by Brislin (1976) - translation by native speaker of the selected country. We finalized the items by asking three experts in each country to respond.

\section{RESULTS}

As mentioned in theoretical background different nations perceive AG differently. Some people are more negative to the AG than others. Therefore we focused deeply on this dissonance. Results of the international survey drawn to detect those differences, we observed that Ukrainians are significantly different than other nations studied by their centrist attitudes toward ads. Americans attitude is more positive and Germans more negative (see Table 3).

Tab. 3 - Attitude towards advertising in general (AG). Source: authors' research.

\begin{tabular}{|c|c|c|c|c|}
\hline & $\mathrm{N}$ & AVG & F test significance & Rejection of $\mathrm{H}_{0}$ \\
\hline USA & 90 & 5.189 & \multirow{2}{*}{0.003} & \multirow{2}{*}{ Yes } \\
\hline UA & 108 & 4.787 & & \\
\hline USA & 90 & 5.189 & \multirow{2}{*}{0.925} & \multirow{2}{*}{ No } \\
\hline GE & 78 & 4.462 & & \\
\hline UA & 108 & 4.787 & \multirow{2}{*}{0.003} & \multirow{2}{*}{ Yes } \\
\hline GE & 78 & 4.462 & & \\
\hline
\end{tabular}

ANOVA, $\alpha=0.05$

Questionnaire: Part A, Q6: What is your opinion about advertising in general?

a) Overall, I consider advertising a good thing

It seems strange that nations with more negative and more positive AG are not significantly different between each other opposed to the significantly different Ukraine. Ukrainians are less optimistic than US respondents; and according to AG Ukrainians are more optimistic than German respondents. This relation of output behavior needs to be supported by its sources to reach cause and effect explanation.

Similar difference was confirmed for billboard ads only for Ukrainian and German respondents, not for the USA (Table 4). Significant differences at 0.05 are bold marked in the table 4.

Tab. 4 - Attitude of countries towards advertising in general (AG) on billboards. Source: authors' research.

\begin{tabular}{|l|c|c|c|}
\hline & UA & GE & USA \\
\hline UA & & $\mathbf{0 . 0 2 1 7 8}$ & 0.23021 \\
\hline GE & $\mathbf{0 . 0 2 1 7 8}$ & & 0.25739 \\
\hline USA & 0.23021 & 0.25739 & \\
\hline
\end{tabular}

Questionnaire: Part A, question $7 \mathrm{f}, \mathrm{g}, \mathrm{h}$ 
Because the difference was expected, we used in the survey question focusing on the culture of the respondent nation. One of the questions related to the culture was religion of the respondents. The results shown different religion really impact the attitude toward the ad. Table 5 shows the same differences between German and Ukrainian respondents as we observed them in table 4 . The difference can be explained by significantly different religions of respondents in researched countries (Table 5).

Tab. 5 - Religion. Source: authors’ research.

\begin{tabular}{|c|c|c|c|c|c|c|}
\hline & \multicolumn{2}{|c|}{ UA } & \multicolumn{2}{c|}{ USA } & \multicolumn{2}{c|}{ GE } \\
\hline test & ANOVA & $\chi^{2}$ test & ANOVA & $\chi^{2}$ test & ANOVA & $\chi^{2}$ test \\
\hline UA & & & $\mathbf{0 . 0 0 0}$ & $\mathbf{0 . 0 0 0}$ & $\mathbf{0 . 0 0 4}$ & 0.584 \\
\hline USA & $\mathbf{0 . 0 0 0}$ & $\mathbf{0 . 0 0 0}$ & & & $\mathbf{0 . 0 0 0}$ & $\mathbf{0 . 0 0 0}$ \\
\hline GE & $\mathbf{0 . 0 0 4}$ & 0.584 & $\mathbf{0 . 0 0 0}$ & $\mathbf{0 . 0 0 0}$ & & \\
\hline
\end{tabular}

$\alpha=0.005$

Questionnaire: Part C, Q19: On a spiritual point of view, you would describe yourself as: Catholic, Protestant, Orthodox, Muslim, Jewish, Atheist, Other.

Table 5 shows differences in religion tested by ANOVA and $\chi^{2}$ test. Table 5 uses religion to explain the opposite polarity of AG (more positive or more negative) of surveyed countries. Centric position of Ukrainian respondents between religions of respondents from Germany and USA was confirmed again by significant differences between religion of respondents from Germany and USA. The respondents from Germany were mainly Protestants; this homogeneity of the sample clearly shown the expected difference between religions and thus the difference between AG and Aad answers. Anyway, the respondents were separately tested for homogenous samples and then according to their nation. The respondents from Ukraine and USA were not as homogenous in their religions as in Germany; there were found statistically significant differences between Catholics and Protestants.

Different position of Ukrainians towards $A G$ is broadened and extended in attitude towards brand (Ab) according to the results of ANOVA in part $\mathrm{C}$ of the questionnaire. As Ukrainians are mainly Orthodox or Atheists, it is possible to conclude that those respondents have significantly different attitude than religions of other respondents. Orthodox and Atheist religions are therefore different in perception of AG (Table 6).

Tab. 6 - Religion towards AG. Source: authors' research.

\begin{tabular}{|l|c|c|c|c|c|c|c|}
\hline \multicolumn{1}{|c|}{ F test } & Catholic & $\begin{array}{c}\text { Protes- } \\
\text { tant }\end{array}$ & $\begin{array}{c}\text { Ortho- } \\
\text { dox }\end{array}$ & Muslim & Jewish & Atheist & Other \\
\hline Catholic & & 0.265 & $\mathbf{0 . 0 0 1}$ & 0.194 & No data & $\mathbf{0 . 0 0 4}$ & 0.099 \\
\hline Protestant & 0.265 & & $\mathbf{0 . 0 0 0}$ & 0.252 & No data & $\mathbf{0 . 0 0 0}$ & $\mathbf{0 . 0 0 8}$ \\
\hline Orthodox & $\mathbf{0 . 0 0 1}$ & $\mathbf{0 . 0 0 0}$ & & 0.075 & No data & 0.910 & 0.314 \\
\hline Muslim & 0.194 & 0.252 & 0.075 & & No data & 0.073 & 0.111 \\
\hline
\end{tabular}




\begin{tabular}{|l|c|c|c|c|c|c|c|}
\hline Jewish & No data & No data & No data & No data & & No data & No data \\
\hline Atheist & $\mathbf{0 . 0 0 4}$ & $\mathbf{0 . 0 0 0}$ & 0.910 & 0.073 & No data & & 0.337 \\
\hline Other & 0.099 & $\mathbf{0 . 0 0 8}$ & 0.314 & 0.111 & No data & 0.337 & \\
\hline
\end{tabular}

ANOVA, $\alpha=0.005$

Questionnaire: Part A, Q6, Part C, Q19: On a spiritual point of view, you would describe yourself as: Catholic, Protestant, Orthodox, Muslim, Jewish, Atheist, Other.

The found AG differences can be explained by need for cognition of Orthodox and Atheist respondents as a source condition in both periods before any ad (questionnaire part A) and after the brand was displayed (questionnaire part C). These findings may explain why Atheists and Orthodox respondents declare immunity towards global standardized advertising campaigns in literature very often. It shows mistake of researchers, who have finished with AG questions without testing Aad and Bi.

We have revealed that AG is different in Ukraine because of the history of religion. Additionally, it is possible that resulted attitudes may be transferred into ASG or brands. The tables below (Tab. 7 - 8) show the results of tests focused on the differences between ASG and Aad in selected countries. Firstly, differences between hard sell and soft sell - attitude towards specific ad (Aad) were tested.

Tab. 7 - Hard sell vs. soft sell - attitude towards specific ad (Aad). Source: authors' research.

\begin{tabular}{|l|c|c|c|c|}
\hline & $\mathrm{N}$ & AVG & F test significance & Rejection of $\mathrm{H}_{0}$ \\
\hline USA & 90 & 2.367 & 0.743 & No \\
\hline UA & 108 & 4.139 & 0.541 & No \\
\hline GE & 78 & 2.449 & 0.576 & No \\
\hline
\end{tabular}

ANOVA, $\alpha=0.05$

Questionnaire: Part B, Q10: To what extent do you like or dislike this ad?

No significant difference was found. We may say that the specific ad or brand attract the respondent's attitude in the same way. The extreme behavior disappears. This supports the overall known fact that the very same ads are successful no matter the country, religion or nation. Table 7 also shows that there is basically no difference between hard sell and soft sell ad. Both types of specific ads are perceived in the same way.

To validate this output, the differences between hard sell and soft sell focused on brand intention (Bi) were tested. As it is possible to see in Table 8, we received the same result. There is no difference between hard and soft sell appeal. Respondents perceived it in the same way. 
Tab. 8 - Hard sell vs. soft sell - attitude towards unknown brand (Ab). Source: authors' research.

\begin{tabular}{|l|c|c|c|c|}
\hline & N & AVG & F test significance & Rejection of $\mathrm{H}_{0}$ \\
\hline USA & 90 & 2.739 & 0.229 & No \\
\hline UA & 108 & 4.107 & 0.644 & No \\
\hline GE & 78 & 2.423 & 0.968 & No \\
\hline
\end{tabular}

ANOVA, $\alpha=0.05$

Questionnaire: Part B, Q11: How much do you think this advertising has affected your attitude toward AZZ?

Thirdly, we re-test mentioned output (statement: there is no difference in attitude toward specific ad or a brand using hard sell or soft sell advertising) by comparison of the countries. Table 9 shows results of tests focused on hard sell $\mathrm{Aad}$ and $\mathrm{Ab}$ and soft sell Aad and Ab. Table shows only the results of ANOVA.

Tab. 9 - Attitude towards specific ad (Aad) and attitude towards brand (Ab). Source: authors' research.

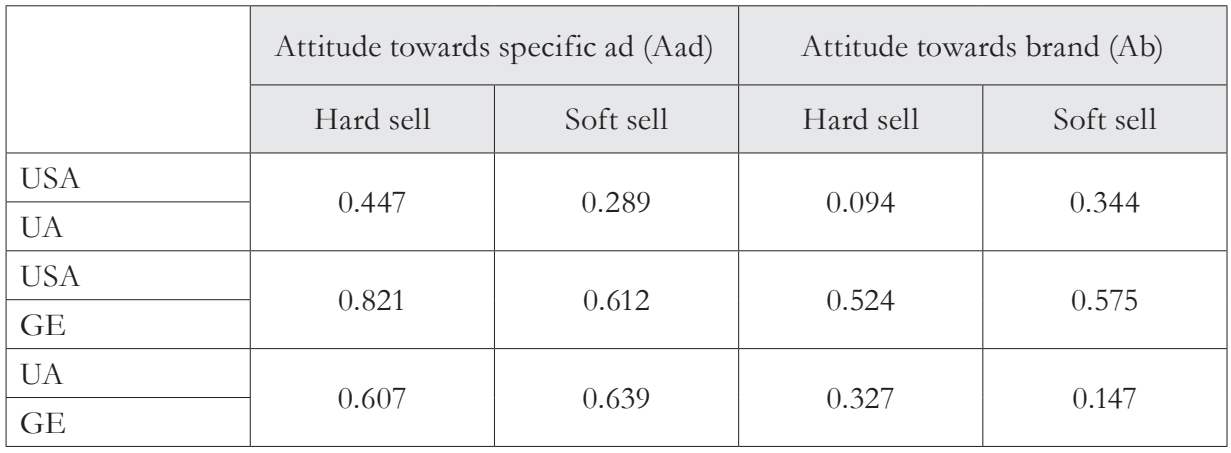

ANOVA, $\alpha=0.05$

Questionnaire: Part B, Q10: To what extent do you like or dislike this ad? And Q11: How much do you think this advertising has affected your attitude toward AZZ?

As the Table 9 shows, no significant differences were found. All respondents from all selected countries have the same attitude toward specific ads and brands and the reaction is the same whether they see just a picture of the product or they read more information about it.

To make sure there are really no dependencies, we used correlation analysis. Table 10 analyzed the relations between countries according to the religion. The results gained are the same. Correlations or associations were tested and no correlations between countries and religions were found. The test has denied any similarity between countries concerning religion. The Spearman's coefficient of correlation was used according to the type of the data (Table 10). 
Tab. 10 - Correlations between countries according to the religion (Spearman's coefficient). Source: authors' research.

\begin{tabular}{|c|c|c|c|c|}
\hline \multicolumn{2}{|c|}{ Spearman's rho } & UA & USA & GE \\
\hline \multirow{3}{*}{ UA } & Correlation Coefficient & 1.000 & -.008 & .148 \\
\cline { 2 - 5 } & Sig. (2-tailed) &. & .942 & .196 \\
\cline { 2 - 5 } & $\mathrm{N}$ & 108 & 90 & 78 \\
\hline \multirow{3}{*}{ USA } & Correlation Coefficient & -.008 & 1.000 & .111 \\
\cline { 2 - 5 } & Sig. (2-tailed) & .942 &. & .335 \\
\cline { 2 - 5 } & $\mathrm{N}$ & 90 & 90 & 78 \\
\hline \multirow{2}{*}{ GE } & Correlation Coefficient & .148 & .111 & 1.000 \\
\hline \multirow{3}{*}{} & Sig. (2-tailed) & .196 & .335 &. \\
\cline { 2 - 5 } & $\mathrm{N}$ & 78 & 78 & 78 \\
\hline
\end{tabular}

Spearman's coefficient of correlation have shown equal result as previous tests; neither similarity, nor significance.

Finally, correlations between countries and AG were processed. Tab. 11 shows the results of correlation between attitude towards advertising in general (AG) and selected countries.

Tab. 11 - Correlation between countries according to AG (Pearson's coefficient). Source: authors' research.

\begin{tabular}{|c|c|c|c|c|}
\hline \multicolumn{2}{|c|}{} & UA & GE & USA \\
\hline \multirow{3}{*}{ UA } & Pearson Correlation & 1 & .010 & -.072 \\
\cline { 2 - 5 } & Sig. (2-tailed) & & .934 & .499 \\
\cline { 2 - 5 } & N & 108 & 78 & 90 \\
\hline \multirow{3}{*}{ GE } & Pearson Correlation & .010 & 1 & -.008 \\
\cline { 2 - 5 } & Sig. (2-tailed) & .934 & & .944 \\
\cline { 2 - 5 } & N & 78 & 78 & 78 \\
\hline \multirow{3}{*}{ USA } & Pearson Correlation & -.072 & -.008 & 1 \\
\cline { 2 - 5 } & Sig. (2-tailed) & .499 & .944 & 90 \\
\cline { 2 - 5 } & N & 90 & 78 & \\
\hline
\end{tabular}

Tab. 11 shows neither similarly, nor significant correlations. No significant differences in Tab. 9 - 11 have shown that respondents from each country have reacted equally after various additional information regarding ad or brand is displayed. This output explains efficiency of global advertising campaigns.

\section{DISCUSSION}

The hypothesis that the advertising is conform to the ad standard expected by consumer (when he answers to the questions on $A G$ ) was rejected. Also observation of relationship between AG 
and Aad (represented by Mehta, 2000) was rejected. It is possible to say that the relationship between AG and Aad has been observed only in certain circumstances and could be not observed in all tested situations. Relationship between AG and Aad differs based on the general advertising reference the consumer has in his mind when he answers to the questions. This means that the result sated by Soo and Chia (2007) was confirmed.

The general attitude which influences Aad could have significant distortions depending on the type of advertising used. It depends on the fact that liking the advertising in general can differ from liking a particular type of ad. Additionally, we may say that the specific ad or brand attract the respondent's attitude in the same way. The extreme behavior disappears. This supports the overall known fact that the very same ads are successful no matter the country, religion or nation. Results show that there is basically no difference if the hard sell or a soft sell ad is used. Both are perceived in the same way.

We may speculate, for purpose of further research, that Ukrainians may have problem with low material welfare and short term orientation (Hofstede, 2005) when ASG is displayed. It is possible to observe differences between enculturation and cognition depends on the use of brain while looking at the ad - whether the respondent use his cognitive abilities. Interesting finding is that material culture of Ukrainians, scientific training of atheists and short term orientation cause enculturation, which might deny preliminary attitudes of respondent. Thus it causes positive reaction on global advertising campaigns. The AG differences disappear within global campaigns. It is supported by the results of other studies stating the very same ads are successful no matter the country, religion or nation. For example, central position of Ukraine among more positive and more negative countries towards AG is sign of cultural standardization. The enculturation (Washburn, 2008) is sign of cultural adaptation, which would allow prediction of no significant differences between $\mathrm{Aad}, \mathrm{Ab}$ and $\mathrm{Bi}$ in global marketing campaigns recently. Additionally, hypotheses about impact of material level of the life, short term cultural orientation and high or low context language on hard-sell or soft-sell ads need to be clarified in future researches.

\section{CONCLUSIONS}

The concept of AG is in some cases too broad. Therefore, the objective of the paper was to replace AG by more accurate measurements of ASG which focus on specific features of ads. But presented results have not shown differences between ASG ads found here is contradictory with difference between answers on ASG due to conditions. The hypothesis 'H1: Aad towards different ASG will modify Ab or Bi in standardised conditions of countries and religions of respondents.' was denied. Therefore, the impact of social approval doesn't differentiate Aad between respondents in studied countries with different culture and religions.

On the other hand the differences between AG were confirmed between Ukraine and other countries. The differences between Bi have confirmed orthodox and atheist religions as source condition when asking generally about advertising. No confirmed differences between hardsell and soft-sell ads deny the effect of these subcategories of AG. The respondents from Germany are according to AG more pessimistic and from USA more optimistic. This difference was explained by significant difference of Orthodox and Atheist religion compare to the other 
religions. The findings explain important sources, which advertiser or manager should take into account to deal with new employee or customer. Still the research focused on students and thus the results are not fully representative. Still, there are gaps in this area. Thus future research in this field should focus on deeper analysis of the phenomenon using more representative sample of respondents. The basic analysis presented in this paper showed general attitudes towards ad, specific ad and advertising in general, but future analyses should focus on deeper analysis and relationship between selected concepts and its causes and consequences. Still, there are gaps in current research in this area. The possibility of practical use of the results stimulates research into the topic.

\section{References}

1. Baker, W. E., \& Lutz, R. J. (2000). An Empirical Test of an Updated RelevanceAccessibility Model of Advertising Effectiveness. Journal of Advertising, 29(1), 1-14. http:// dx.doi.org/10.1080/00913367.2000.10673599

2. Bhat, S., Leigh, T. W., \& Wardlow, D. L. (1998). The Effect of Consumer Prejudice on Ad Processing: Heterosexual Consumers' Responses to Homosexual Imagery in Ads. Journal of Advertising, 27(4), 9-29. http://dx.doi.org/10.1080/00913367.1998.10673566

3. Brislin, R. (1976). Comparative research methodology: Cross-cultural studies. International Journal of Psychology, 11(3), 215-229. http://dx.doi.org/10.1080/00207597608247359

4. Bush, A. J., Smith, R., \& Martin, C. (1999). The Influence of consumer socialization variables on attitude toward advertising: A comparison of African-Americans and Caucasians. Journal of Advertising, 28(3), 13-24. http://dx.doi.org/10.1080/00913367.1999.10673586

5. Coulter, K. (1998). The Effects of Affective Responses to Media Context on Advertising Evaluation. Journal of Advertising, 27(4), 41-50. http://dx.doi.org/10.1080/00913367.1998.106 73568

6. Derbaix, C. M. (1995). The Impact of Affective Reactions on Attitudes toward the Advertisement and the Brand: A Step toward Ecological Validity. Journal of Marketing Research, 32(4), 470-479. http://dx.doi.org/10.2307/3152182

7. Dianoux, C., Linhart, Z., \& Ogjanov, G. (2012). A Cross-European Perspective on Attitudes toward Advertising in General and Attitude toward an Ad. In. 41th Annual Conference of European Marketing Academy (pp.357-359).

8. Dianoux, C., \& Linhart, Z. (2012). The Attitude Toward Advertising in General and Attitude Toward Specific Ads: Is It the Same Influence Whatever the Countries? In. Symposium of 20th Annual Conference on Marketing and Business Strategies for Central and Eastern Europe (pp.121-129).

9. Dianoux, C., \& Linhart, Z. (2010). The effectiveness of female nudity in advertising in three European countries. International Marketing Review, 27(5), 562-578. http://dx.doi. org/10.1108/02651331011076590 
10. Donthu, N. J., Cherian, J., \& Bhargava, M. (1993). Factors Influencing Recall of Outdoor Advertising. Journal of Advertising Research, 33(3), 64-72.

11. Durvasula, S., Andrews, J. C., Lysonski, S., \& Netemeyer, R. G. (1993). Assessing the Cross-national Applicability of Consumer Behavior Models: A Model of Attitude toward Advertising in General. Journal of Consumer Research, 19(4), 626-636. http://dx.doi. org $/ 10.1086 / 209327$

12. Durvasula, S., Lysonski, S., \& Mehta, S. C. (1999). A Cross-Cultural Comparison of Cognitive Responses, Beliefs, And Attitudes Toward Advertising In General In Two Asian Countries. Journal of Marketing Management, 9(3), 48-59.

13. Gardner, M. P. (1985). Does Attitude Toward the Ad Affect Brand Attitude Under a Brand Evaluation Set? Journal of Marketing Research, 22(2), 192-198. http://dx.doi. org $/ 10.2307 / 3151364$

14. Hofstede, G., \& Bond, M. H. (1988). The Confucius connection: From cultural roots to economic growth. Organizational Dynamics, 16(1), 4-21. http://dx.doi.org/10.1016/00902616(88)90009-5

15. Hofstede, G., \& Hofstede, G. J. (2005). Cultures and organizations: software of the mind. New York: McGraw-Hill.

16. James, W. L., \& Kover, A. J. (1992). Observations: do overall attitudes toward advertising affect involvement with specific advertisements? Journal of Advertising Research, 32(5), 78-83.

17. Kapferer, J. N., \& Laurent, G. (1986). Consumer involvement profiles: A new practical approach to consumer involvement. Journal of Advertising Research, 25(6), 48-56.

18. Kirmani, A., \& Campbell, M. C. (2009). Taking the target's perspective: The persuasion knowledge model. In: Wänke, M. Social Psychology of Consumer Behavior. New York: Taylor \& Francis. (pp. 297-316).

19. Lutz, R. J. MacKenzie, S. B., \& Belch, G. E. (1983). Attitude toward the ad as a mediator of advertising effectiveness: Determinants and consequences. Advances in consumer research, 10(1), 532-539.

20. MacKenzie, S. B., Lutz, R. J., \& Belch, G. E. (1986). The Role of Attitude toward the Ad as a Mediator of Advertising Effectiveness: A Test of Competing Explanations. Journal of Marketing Research, 23(2), 130-143. http://dx.doi.org/10.2307/3151660

21. MacKenzie, S. B., \& Lutz, R. J. (1989). An Empirical Examination of the Structural Antecedents of Attitude toward the Ad in an Advertising Pretesting Context. Journal of Marketing, 53(2), 48-65. http://dx.doi.org/10.2307/1251413

22. MacKenzie, S. B. (1986). The role of attention in mediating the effect of advertising on attribute importance. Journal of Consumer Research, 13(2), 174-195. http://dx.doi. org/10.1086/209059 
23. Mehta, A. (2000). Advertising Attitudes and Advertising Effectiveness. Journal of Advertising Research, 40(3), 67-72.

24. Mitchel, A. A., \& Olson, J. C. (1981). Are Product Attribute Beliefs the Only Mediator of Advertising Effects on Brand Attitude? Journal of Marketing Research, 18(3), 318-332. http:// dx.doi.org/10.2307/3150973

25. de Mooij, M. (2000). The future is predictable for international marketers: Converging incomes lead to diverging consumer behavior. International Marketing Review, 17(2), 103-113. http://dx.doi.org/10.1108/02651330010322598

26. de Mooij, M. (2003). Convergence and divergence in consumer behaviour: Implications for global advertising. International Journal of Advertising. 22(1), 183-202.

27. Muehling, D. D. (1987). An Investigation of Factors Underlying Attitude-TowardAdvertising-In-General. Journal of Advertising, 16(1), 32-40. http://dx.doi.org/10.1080/00913 367.1987.10673058

28. Muehling, D. D., \& McCann, M. (1993). Attitude toward the Ad: A Review. Journal of Current Issues \& Research in Advertising, 15(2), 25-59. http://dx.doi.org/10.1080/10641734.1993.10505 002

29. Okazaki, S., Mueller, B., \& Taylor, C. R. (2010). Measuring soft-sell versus hard-sell advertising appeals. Journal of Advertising, 39(2), 5-20. http://dx.doi.org/10.2753/JOA00913367390201

30. Percy, L., \& Rossiter, J. R. (1992). Advertising Stimulus Effects: A Review. Journal of Current Issues \& Research in Advertising, 14(1), 75-90. http://dx.doi.org/10.1080/10641734.1992.10504 982

31. Petrovici, D., \& Marinov, M. (2007). Determinants and antecedents of general attitudes towards advertising: A study of two EU accession countries. European Journal of Marketing, 41(3/4), 307-326. http://dx.doi.org/10.1108/03090560710728354

32. Pollay, R. W., \& Mittal, B. (1993). Here's the beef: factors, determinants, and segments in consumer criticism of advertising. Journal of Marketing, 57(3), 99-115. http://dx.doi. org $/ 10.2307 / 1251857$

33. Roberts, J. A. (2000). Consuming in a consumer culture: College students, materialism, status consumption, and compulsive buying. Marketing Management Journal, 10(1), 769-781.

34. Rojas-Méndez, J. I., Davies, G., \& Madran, C. (2009). Universal differences in advertising avoidance behavior: A cross-cultural study. Journal of Business Research, 62(10), 947-954. http://dx.doi.org/10.1016/j.jbusres.2008.08.008

35. Sandage, C. H., \& Leckenby, J. D. (1980). Student Attitudes toward Advertising: Institution vs. Instrument. Journal of Advertising, 9(2), 29-44. http://dx.doi.org/10.1080/00913367.1980. 10673316 
36. Shimp, T. A. (1981). Attitude toward the Ad as a Mediator of Consumer Brand Choice. Journal of Advertising, 10(2), 9-48. http://dx.doi.org/10.1080/00913367.1981.10672756

37. Soo, J. T., \& Chia, L. (2007). Are we measuring the same attitude? Understanding media effects on attitude towards advertising. Marketing Theory, 7(4), 353-377. http://dx.doi. org/10.1080/10.1177/1470593107083162

38. Washburn, D. (2008). Enculturation and the Degenerative Principle. Contemporary issues, $1(1), 49-61$.

\section{Contact information:}

Prof. Christian Dianoux

CEREFIGE - University of Lorraine - IUT

Ile du Saulcy

57045 Metr, France

Email:christian.dianoux@univ-metr.fr

doc. Ing. Zdeněk Linhart, CSc.

Ceská zemèdèlské univerzita v Praze

Provozně ekonomická fakulta, katedra rízení

Kamýcké 129

16521 Praha 6, Ceská republika

Email:linhart@pef.czu.cz.

Ing. Lucie Vnoučková, Ph.D.

Vysoká skoola ekonomie a managementu

Nárožni 2600/9a

15800 Praba 5, Ceská republika

Email:lucie.vnouckova@vsem.cr. 